\title{
Catalytic upgrading of pretreated algal bio-oil over zeolite catalysts in supercritical water
}

\author{
Peigao Duan ${ }^{1, *}$, Yuping $\mathrm{Xu}^{1}$, Feng Wang ${ }^{1, *}$, Bing Wang ${ }^{1}$, Weihong Yan $^{2}$ \\ 1. College of Physics and Chemistry, Department of Applied Chemistry, Henan Polytechnic University, No. 2001, \\ Century Avenue, Jiaozuo, Henan 454003, P.R. China
}

2. School of Biology and Chemistry Engineering, Nanyang Institute of Technology, Nanyang, Henan 473004, PR China

\begin{abstract}
We report the catalytic hydrothermal upgrading of pretreated algal bio-oil. The reaction was performed at $400{ }^{\circ} \mathrm{C}$ for 240 min with the addition of $6 \mathrm{MPa}_{2}$ and 10 wt. $\%$ zeolite catalyst in supercritical water $\left(\rho_{\mathrm{H} 2 \mathrm{O}}=0.025 \mathrm{~g} / \mathrm{cm}^{3}\right)$. Nine zeolites $\left(\mathrm{H} \beta, \mathrm{HZSM}-5\left(\mathrm{SiO}_{2} / \mathrm{Al}_{2} \mathrm{O}_{3}=25: 1\right), \mathrm{HZSM}-5\right.$ $\left(\mathrm{SiO}_{2} / \mathrm{Al}_{2} \mathrm{O}_{3}=50: 1\right), \mathrm{HZSM}-5\left(\mathrm{SiO}_{2} / \mathrm{Al}_{2} \mathrm{O}_{3}=170: 1\right), \mathrm{HY}\left(5 \% \mathrm{Na}_{2} \mathrm{O}\right), \mathrm{HY}\left(0.8 \% \mathrm{Na}_{2} \mathrm{O}\right)$, SAPO-11, MCM-41 (50\% Si), and MCM-41 (100\% Si)) were screened to investigate their effects on the yields of the product fraction and the properties (e.g., elemental composition and heating value) of the upgraded bio-oil. The catalyst type affected the yields of the product fractions: SAPO-11 produced the lowest upgraded bio-oil yield of 42.4 wt.\%, and MCM-41 provided the highest yield of 54.5 wt.\%. Compared with non-catalytic upgrading reactions, all of the zeolites promoted the denitrogenation, deoxygenation, and desulfurization of the pretreated bio-oil due to the presence of acid sites. HY $\left(5 \% \mathrm{Na}_{2} \mathrm{O}\right)$, $\mathrm{HY}\left(0.8 \% \mathrm{Na}_{2} \mathrm{O}\right)$, and $\mathrm{HZSM}-5\left(\mathrm{SiO}_{2} / \mathrm{Al}_{2} \mathrm{O}_{3}=25: 1\right)$ showed the highest activity toward denitrogenation, deoxygenation, and desulfurization, respectively. The upgraded bio-oil mainly consisted of hydrocarbons, accounting for $80 \%$ in total and as high as $95.6 \%$ of the fraction below $400{ }^{\circ} \mathrm{C}$.
\end{abstract}

Keywords: Microalgae; hydrothermal liquefaction; pretreatment; upgraded; zeolites; upgraded bio-oil

\footnotetext{
*Corresponding author: Department of Applied Chemistry, Henan Polytechnic University, No. 2001, Century Avenue, Jiaozuo, Henan 454003, P.R. China; Tel: +86 (0391) 3986820; fax: +86 (0391) 3987815

E-mail address: pgduan@hpu.edu.cn (P.-G. Duan); smallpeak@hpu.edu.cn (F. Wang)
} 


\section{Introduction}

As one of the most important types of renewable biomass, microalgae have received increasing attention from both the academic community and industry due to their wide distribution, high photosynthetic efficiency, strong environmental adaptability, and short harvesting cycle. Therefore, microalgae utilization and conversion technology has become a new direction in the field of international renewable energy and a topic of interest for many researchers. To date, the utilization of microalgae has mainly focused on the production of biodiesel [1-4]. However, two major barriers are encountered during the large-scale production of biodiesel from microalgae using the traditional method: the screening and cultivation of algal species with high lipid contents and the required drying and extraction of the harvested algae to obtain the lipid. Therefore, many key technologies are required in addition to the initial investment, energy consumption, and low utilization rate of the raw materials. Thus, the research and development of new methods for the conversion of microalgae to liquid biofuels is a top priority.

Hydrothermal conditions are broadly defined as the use of a water-rich phase above $200{ }^{\circ} \mathrm{C}$ in conducting chemical reactions. Hydrothermal conditions are also known as subcritical water $\left(<150-374{ }^{\circ} \mathrm{C}, 0.4-22.1 \mathrm{MPa}\right)$ and supercritical water(SCW) $\left(>374{ }^{\circ} \mathrm{C},>22.1 \mathrm{MPa}\right)$. Both types of water are non-toxic and environmentally friendly media with good mass transfer and heat transfer characteristics [5]. The properties of water, such as the density and dielectric constant, can be continuously controlled between gas-like and liquid-like values by varying the temperature and pressure. For example, at a pressure of $25 \mathrm{MPa}$, the dielectric constant decreases from approximately 78 at $25{ }^{\circ} \mathrm{C}$ to 27 at $250{ }^{\circ} \mathrm{C}$ and to 2 at $400{ }^{\circ} \mathrm{C}$ [5]. This decrease in dielectric constant increases the solubility of small organic compounds. Thus, the polarity of water and hence its ability to dissolve various solids, liquids, and gases that are otherwise insoluble or sparingly soluble can be significantly enhanced by transforming ordinary water into supercritical water. In addition, water at subcritical conditions can act as an acid or base catalyst, whereas supercritical water offers the unique possibility of shifting the dominant reaction mechanisms from free radical 
to ionic through manipulation of the water's density. However, many potential feedstocks, especially microalgae, have very high moisture contents. Therefore, hydrothermal processing of such biomass feedstocks is attractive from an energy perspective. The term "hydrothermal" used here refers to the processing of microalgae in water slurries at elevated temperature and pressure to facilitate the chemical conversion of the organic structures in the microalgae into useful fuels or chemicals. The process is meant to provide a means for treating wet biomass materials without drying and to access ionic reaction conditions by maintaining a liquid water processing medium.

Within the regime of hydrothermal processing, there are two main process groups: hydrothermal liquefaction and hydrothermal gasification. Hydrothermal liquefaction (also known as direct liquefaction), a traditional process, is accomplished at the lower end of the process temperature range $\left(<370{ }^{\circ} \mathrm{C}\right)$ to obtain bio-oil. Hydrothermal gasification is accomplished at the upper end of the process temperature range $\left(<370{ }^{\circ} \mathrm{C}\right)$ and can be considered an extension of the liquefaction mechanisms with subsequent decomposition of large molecules to smaller molecules and eventually to gas. In recent years, reports on the hydrothermal liquefaction of microalgae have increased significantly, and the vast majority has focused on the liquefaction behavior of different types of microalgae and the influence of experimental conditions on the components of the resulting bio-oil [6-9]. However, the bio-oil produced from the hydrothermal liquefaction of microalgae cannot be used directly due to its high viscosity and high $\mathrm{N}$ and $\mathrm{S}$ contents. Further treatment is required if a fungible transportation fuel is to be produced from this type of crude bio-oil. To date, the upgrading of crude bio-oil produced from the hydrothermal liquefaction of microalgae is rare. Duan and Savage [10] performed pioneering work on the upgrading of crude bio-oil derived from the hydrothermal liquefaction of microalgae in SCW. The SCW reaction medium alone appeared to allow for the complete desulfurization of the crude algal bio-oil, and the abundance of $\mathrm{N}$ and $\mathrm{O}$ in the treated bio-oils was considerably reduced. Subsequent studies $[11,12]$ have demonstrated that the type of catalyst is the most influential factor affecting the fraction of $\mathrm{N}$ - and O-containing compounds and saturated hydrocarbons that remained in the upgraded bio-oil. Moreover, the 
presence of SCW could effectively reduce coke formation. Duan and coworkers [13-15] performed a series of studies on the upgrading of algal biocrude in SCW. Their results also suggest that the catalyst is a crucial factor significantly affecting the quality of the upgraded bio-oil and the cost of algal biofuel. Compared to expensive noble metal catalysts, inexpensive zeolite (HZSM-5) catalysts have also demonstrated good activities towards the denitrogenation, deoxygenation, and desulfurization of crude algal bio-oil. Furthermore, zeolites can facilitate cracking reactions that will convert the heavier components of the bio-crude into smaller fuel-range molecules [16-20]. Therefore, zeolites are considered potential catalysts for the large-scale production of algal biofuel.

In the present study, a three-stage hydrothermal processing was applied to a) liquefy dry microalgal biomass to generate crude algal bio-oil, b) hydro-pretreat the crude algal bio-oil to obtain pretreated bio-oil, and c) upgrade the pretreated bio-oil to produce upgraded bio-oil. We primarily focused on the third upgrading step, utilizing hydrogen as well, to render a bio-crude with lower $\mathrm{N}$ and $\mathrm{S}$ contents that is a more suitable feedstock for further refinery upgrading.

The purpose of this study was to screen the activity of nine different potential zeolite catalysts (Hß, HZSM-5 ( $\left.\mathrm{SiO}_{2} / \mathrm{Al}_{2} \mathrm{O}_{3}=25: 1\right), \mathrm{HZSM}-5\left(\mathrm{SiO}_{2} / \mathrm{Al}_{2} \mathrm{O}_{3}=50: 1\right), \mathrm{HZSM}-5\left(\mathrm{SiO}_{2} / \mathrm{Al}_{2} \mathrm{O}_{3}=170: 1\right), \mathrm{HY}$ $\left(5 \% \mathrm{Na}_{2} \mathrm{O}\right), \mathrm{HY}\left(0.8 \% \mathrm{Na}_{2} \mathrm{O}\right), \mathrm{MCM}-41(50 \% \mathrm{Si}), \mathrm{MCM}-41(100 \% \mathrm{Si})$, and SAPO-11) for the hydrothermal upgrading of pretreated algal bio-oil. Some of the zeolites used lack long-term stability in a hydrothermal environment, but we did not disqualify any of the catalysts from consideration because of this process-related issue. Rather, we chose to be inclusive of the catalysts because our goal was to determine whether these materials would be effective in short-term upgrading experiments. If a material that lacks long-term stability exhibits promising short-term effects, then additional work can be performed to develop different formulations that are both active and stable. A biocrude produced from the hydrothermal liquefaction of Chlorella p. was selected and hydrothermally pretreated with added hydrogen to reduce the contents of $\mathrm{N}$ and $\mathrm{S}$, which are potential poisons of the catalyst during processing. The pretreated bio-oil was then used as the feedstock for the zeolite catalyst screening study. The effects of these catalysts on the product yields, 
bulk properties (e.g., elemental composition and heating value), and molecular characteristics (e.g., molecular constituents and functional group allocation) of the upgraded bio-oil were determined.

\section{Experimental section}

\subsection{Materials}

Chlorella p. powder was purchased from Shandong Binzhou Tianjian Biotechnology Co., Ltd. (Binzhou, Shandong province, North China). Its proximate and ultimate analysis, along with other properties, is available in a previous publication [15]. All nine zeolite catalysts, including HZSM-5 $\left(\mathrm{SiO}_{2} / \mathrm{Al}_{2} \mathrm{O}_{3}\right.$ mass ratios of 25:1, 50:1, and 170:1), MCM-41 (100\% Si, 50\% Si), H $\beta$, SAPO-11, and HY $\left(0.8 \% \mathrm{Na}_{2} \mathrm{O}, 5 \% \mathrm{Na}_{2} \mathrm{O}\right)$, were provided by Tianjin University, Tianjin, China. All other chemicals were obtained in high purity from Sigma-Aldrich.

Two custom-made, high-pressure, corrosion-resistant batch reactors were used to carry out the hydrothermal liquefaction, pretreatment, and upgrading experiments. The total internal volume of the reactors used for the hydrothermal liquefaction and upgrading was 1,000 and $58 \mathrm{~mL}$, respectively. Prior to their use in the experiments, the reactors were loaded with water and seasoned at $400{ }^{\circ} \mathrm{C}$ for $4 \mathrm{~h}$ to remove any residual organic material and expose the fresh metal walls to SCW water.

\subsection{Procedures}

\subsubsection{Hydrothermal liquefaction}

Aliquots of $150 \mathrm{~g}$ of algae powder and $400 \mathrm{~mL}$ of deionized water were loaded into the $1,000 \mathrm{~mL}$ reactor. The reactor was heated by an electric jacket with a heating power of $2.5 \mathrm{~kW}$. The mechanical agitator was set at $1,000 \mathrm{rpm}$. The reaction time was the time required for the temperature inside the reactor to reach $350{ }^{\circ} \mathrm{C}$. The highest pressure achieved inside the reactor was $15 \mathrm{MPa}$. A temperature of $350{ }^{\circ} \mathrm{C}$ was selected because it resulted in the highest yield of crude bio-oil from the hydrothermal liquefaction of microalgae [9]. After $60 \mathrm{~min}$, the power was switched off, and the reactor was cooled by the cooling coil contained within. After the reactor had cooled, it was depressurized and opened. Dichloromethane was added to extract the oil fraction and separate 
it from the aqueous phase. The separated aqueous phase can then be reused as the subsequent reaction medium for the pretreatment of crude algal bio-oil. Next, the extract was filtered, and the dichloromethane in the extract was evaporated using a rotary evaporator. The remaining material was the algal biocrude.

\subsubsection{Pretreatment}

Biocrude hydrothermal pretreatment was carried out in the $58 \mathrm{~mL}$ batch reactor, which is unmixed. Aliquots of $10 \mathrm{~g}$ of the algal biocrude and $6 \mathrm{~mL}$ of freshly deionized water were loaded into the reactor. The air inside the reactor was displaced by purging the reactor headspace with hydrogen for approximately $15 \mathrm{~min}$. The reactor was then further charged with hydrogen to $6 \mathrm{MPa}$ (room temperature) to provide a reducing environment.

Pretreatment aimed to pre-lower the $\mathrm{N}$ and $\mathrm{S}$ contents and viscosity of the crude bio-oil. Decreased $\mathrm{N}$ and $\mathrm{S}$ contents in the crude bio-oil decrease the possibility of catalyst poisoning, and decreased viscosity reduces coke formation. Therefore, moderate temperature was more suitable for this process [15]. The loaded reactor was heated using a molten salt bath consisting of potassium nitrate and sodium nitrate at a mass ratio of 5:4. The reactor was placed into the molten-salt bath that was pre-heated to $350{ }^{\circ} \mathrm{C}$. Approximately 20 min later, the reactor reached $350{ }^{\circ} \mathrm{C}$, and the reaction time was initiated. The highest pressure achieved inside the reactor was $22 \mathrm{MPa}$. After $4 \mathrm{~h}$, the reactor was removed from the molten-salt tank and immersed in an ice-water bath for approximately $15 \mathrm{~min}$ to stop the reaction. The subsequent procedure was the same as the recovery of algal biocrude from the hydrothermal liquefaction, as noted above.

\subsubsection{Upgrading}

Upgrading experiments were carried out in a $58 \mathrm{~mL}$ batch reactor, which was un-mixed. In a typical run, $3.0 \mathrm{~g}$ of pretreated bio-oil, $0.3 \mathrm{~g}$ of zeolite, $1.5 \mathrm{~mL}$ of freshly deionized water and 0.126 mol $\mathrm{H}_{2}\left(\sim 6 \mathrm{MPa}_{2}\right)$ were loaded into the reactor. These loadings resulted in a nominal water density of $0.025 \mathrm{~g} / \mathrm{cm}^{3}$ at $400{ }^{\circ} \mathrm{C}$, a catalyst loading of $10 \mathrm{wt} . \%$ relative to pretreated bio-oil, and a water/pretreated bio-oil mass ratio of 1:2. A previous study suggested that $400{ }^{\circ} \mathrm{C}$ is the most 
suitable temperature for the upgrading of crude algal bio-oil in SCW [11]. The remaining steps were similar to the pretreatment process described above.

Pretreated bio-oil upgrading reactions were carried out by placing the reactor in a molten-salt tank preheated to $400{ }^{\circ} \mathrm{C}$. After approximately $30 \mathrm{~min}$, the reactor reached $400{ }^{\circ} \mathrm{C}$, at which point, the reaction time was set to zero. The temperature was controlled at $400 \pm 5^{\circ} \mathrm{C}$ by an Omega temperature controller connected to a thermocouple residing in a thermo-well in the reactor. The highest pressure achieved inside the reactor was $28 \mathrm{MPa}$. After $4 \mathrm{~h}$, the reactor was removed from the molten-salt tank and immersed in an ice-water bath for approximately $15 \mathrm{~min}$ to stop the reaction. The separation procedure of solid and oil is the same as that in a previous study [14].

Independent runs (two or more) runs were conducted under identical conditions to determine the uncertainties of the experimental results. The results reported herein represent the mean of two independent trials. The uncertainties are reported as experimentally determined standard deviations.

\subsection{Characterization}

The total BET surface area, pore volume, and pore size distribution of the zeolites were measured by a Micromeritics ASAP2020 accelerated surface area and porosimetry analyzer. The catalyst sample was placed inside a tube and degassed under a vacuum of $500 \mathrm{mmHg}$ at $350{ }^{\circ} \mathrm{C}$ for $240 \mathrm{~min}$. Then, the sample was transferred to the analysis section to analyze the BET surface area using $\mathrm{N}_{2}$. The surface area was calculated according to the Brunauer-Emmett-Teller (BET) equation. The pore size distribution was obtained from the Horvath-Kawazoe differential pore volume plot. The total BET surface area, pore volume, and pore size distribution of the 9 different zeolites are listed in Table 1. Of the tested zeolites, MCM-41 and SAPO-11 had a small pore volume and BET area, whereas HY had a large pore volume and BET area. HY had the highest BET area, followed by H $\beta$ and HZSM-5. The pore size distribution shows that micropores constituted a large proportion of the H $\beta$, HZSM-5, and HY zeolites. In contrast, mesopores dominated in the MCM-41 and SAPO-11 zeolites. For the HZSM-5 zeolite, increasing the Si/Al molar ratio increased the BET area and pore volume. The mesopore ratio also increased as the $\mathrm{Si} / \mathrm{Al}_{2}$ molar ratio increased. Similar results were 
observed by other researchers [21-23]. For the MCM-41 and HY zeolites, the change in their composition had only a slight effect on the structural properties.

The total acidity and acid strength distribution of the catalyst were estimated by temperature-programed desorption of ammonia ( $\mathrm{NH}_{3}$-TPD) on a Chembet Pulsar TPR/TPD instrument (Quantachrome, USA). For $\mathrm{NH}_{3}$-TPD measurements, a thermal conductivity detector was used to continuously monitor the desorbed ammonia, and the areas under the peaks were integrated to estimate the amount of acid in the catalysts. Approximately $0.5 \mathrm{~g}$ of sample was heated at a rate of $15{ }^{\circ} \mathrm{C} / \mathrm{min}$ to $300{ }^{\circ} \mathrm{C}$ and maintained for $1 \mathrm{~h}$ under a flow of Ar gas $(20 \mathrm{~mL} / \mathrm{min})$ to remove any adsorbed species on the surface. The sample was cooled to $60{ }^{\circ} \mathrm{C}$ under a flow of $\mathrm{Ar}$ gas, followed by adsorption of $\mathrm{NH}_{3}$ under a $10 \% \mathrm{NH}_{3}$ gas flow (balance $\mathrm{Ar}, 20 \mathrm{~mL} / \mathrm{min}$ ) for $1 \mathrm{~h}$. After flushing with $\operatorname{Ar}(20 \mathrm{~mL} / \mathrm{min})$ for $1 \mathrm{~h}$ to remove the physically adsorbed $\mathrm{NH}_{3}$, the TPD data were recorded from 60 to $750{ }^{\circ} \mathrm{C}$ with a ramp of $15{ }^{\circ} \mathrm{C} / \mathrm{min}$. Fig. 2 shows a typical distribution of acid sites, as obtained from the TPD of ammonia. All samples exhibited two well resolved desorption peaks, a low-temperature peak and a high-temperature peak, corresponding to weak and strong acid sites, respectively. The amount of $\mathrm{NH}_{3}$ adsorbed to the weak and strong acid sites of different zeolites are shown in Table 2. The HY series contained a high proportion of weak acid sites, whereas the SAPO-11 and MCM-4 series possessed a high fraction of strong acids sites. The HY series also contained strong acid sites because the peak intensities increased again when the temperature increased beyond $700{ }^{\circ} \mathrm{C}$. The total acid sites of HZSM-5 decreased with an increasing $\mathrm{Si} / \mathrm{Al}$ molar ratio, which agrees well with that reported in the literature [21]. Increasing the proportion of $\mathrm{Na}_{2} \mathrm{O}$ in $\mathrm{HY}$ decreased the fraction of both the weak and strong acid sites.

An Agilent Technologies 7890A GC equipped with an auto-sampler, auto-injector, and mass spectrometric detector (5975C) was used to analyze the crude, pretreated, and upgraded bio-oils. An Agilent J\&W DB-5MS non-polar capillary column (30 m length, $0.25 \mathrm{~mm}$ i.d., and $0.10 \mu \mathrm{m}$ film thickness) was used to separate the constituents. The biocrude, pretreated, and upgraded oil samples were prepared by re-dissolving the bio-oils in dichloromethane at a concentration of $20 \mathrm{wt} . \%$. More 
details are available in Ref. [14].

Elemental analyses, including carbon, hydrogen, oxygen, and nitrogen, were performed on a Thermo Scientific Flash2000 auto-analyzer (Thermo Fisher Scientific, USA). The detailed procedure can be found in Ref [24]. Total S was quantified using the colorimetric titration method on a KZDL-8A sulfur auto-analyzer [25]. The Dulong formula [6] was used to calculate the higher heating value (HHV) of the starting material and all of the bio-oils based on their elemental compositions:

$$
\mathrm{HHV}(\mathrm{kJ} / \mathrm{g})=0.338 \mathrm{C}+1.426(\mathrm{H} / \mathrm{O} / 8)+0.095 \mathrm{~S}
$$

where $\mathrm{C}, \mathrm{H}, \mathrm{S}, \mathrm{O}$, and $\mathrm{N}$ are respectively the carbon, hydrogen, sulfur, oxygen, and nitrogen mass percentages of the material on a dry basis.

Thermogravimetric analysis (TGA) of the crude bio-oil, pretreated bio-oil, and upgraded bio-oils was performed on an SDT Q600 Simultaneous DSC-TGA instrument in a nitrogen atmosphere. The samples were heated from room temperature to $790{ }^{\circ} \mathrm{C}$ at a heating rate of $10{ }^{\circ} \mathrm{C} / \mathrm{min}$. The gas flow rate was $20 \mathrm{~mL} / \mathrm{min}$.

\section{Results and discussion}

\subsection{Effect of zeolites on the yields of the upgraded bio-oil and coke}

Hydrothermal liquefaction and pretreatment produced crude bio-oil and pretreated bio-oil yields of 40 and 83 wt.\%, respectively (on a dry basis relative to their initial corresponding feedstock). Some mass loss is inevitable due to the multiple sample transfers required for separation of the product fractions and the use of evaporation to remove solvents from the samples. Therefore, the lower bound of the yield of each product fraction is reported because mass loss occurred during the handling of each product fraction.

The pretreated bio-oil was converted into upgraded bio-oil, gas, coke, and water-soluble products (WSPs) via hydrothermal processing with added hydrogen and different zeolites, and upgraded bio-oil and coke were the dominant products. Therefore, we focused on the effects of the zeolites on the yields of upgraded bio-oil and coke. Fig. 1 shows the effects of the different zeolite catalysts on 
the yields of the upgraded bio-oil and coke. All of the zeolite catalysts reduced the production of upgraded bio-oil (relative to the noncatalytic treatment) during the hydrothermal processing with added hydrogen. A greater removal of heteroatoms with the zeolite catalysts and the ease of coking and cracking the zeolites are possible reasons for the reduced production of upgraded bio-oil. A decreased upgraded bio-oil yield was also observed in a previous study using HZSM-5 to treat the pretreated algal bio-oil in SCW [14]. Of the examined zeolites, H $\beta$ and SAPO-11 produced upgraded bio-oils with comparatively lower upgraded bio-oil yields, whereas HZSM-5 and MCM-41 provided comparatively higher upgraded bio-oil yields. For HZSM-5, variation in the $\mathrm{Si} / \mathrm{Al}$ molar ratio had no effect on the upgraded bio-oil yield. However, for MCM-41, increasing the Si proportion in the zeolite increased the upgraded bio-oil yield. The presence of most of the zeolites promoted coke formation relative to noncatalytic treatment, which is consistent with a previous study [14]. It is possible that the coke precursor in the bio-oil is approximately the size of a micropore and embedded into the catalyst pores, making it difficult to remove and thus promoting coke formation. For those catalysts with a high proportion of mesopores, a comparatively lower coke yield was observed. $\mathrm{HY}\left(5 \% \mathrm{Na}_{2} \mathrm{O}\right)$, which has a higher proportion of mesopores, also resulted in a lower coke yield than $\mathrm{HY}\left(0.8 \% \mathrm{Na}_{2} \mathrm{O}\right)$. Another possible reason for the lower coke yield produced with MCM-41 is the reaction of the residual template agent in the synthesis of zeolites. The use of different organic template agents such as tetramethylammonium $\left(\mathrm{TMA}^{+}\right.$), tetraethylammonium $\left(\mathrm{TEA}^{+}\right)$, and tetrapropylammonium $\left(\mathrm{TPA}^{+}\right)$leads to distinct dominant structures.

\subsection{Bio-oil characterization}

\subsubsection{Elemental analysis}

Table 3 compares the elemental compositions, higher heating values, energy recoveries (ERs), and energy consumption ratios (ECRs) of the upgraded bio-oils arising from the hydrothermal processing of pretreated bio-oil with different zeolite catalysts. For comparison, the related properties of the microalgae, crude bio-oil, and pretreated bio-oil are also listed in Table 3 . The 
step-wise energy recovery (S-ER) refers to the percentage of energy in the crude bio-oil, pretreated bio-oil, and upgraded bio-oils relative to those quantities in the algae, crude bio-oil, and pretreated bio-oil, respectively. The overall energy recovery (O-ER) refers to the percentage of energy in the upgraded bio-oils relative to those quantities in the initial algae, which was obtained by multiplying the step-wise energy recovery of each step (hydrothermal liquefaction, pretreatment, and upgrading). The ECR was calculated to compare the energy required for thermochemical conversion with the energy that can be recovered from bio-oil combustion, while accounting for combustion energy loss and heat recovery [26,27]; ECR values less than unity indicate a positive energy balance. For the hydrothermal liquefaction(HTL) and pretreatment processes, the ECR values were calculated according to Eq. (1); for the catalytic upgrading process, the ECR values were calculated according to Eq. (2),

$$
\begin{gathered}
E C R_{H T L, \text { pretreatment }}=\frac{\left.\left[x_{\mathrm{H}_{2} \mathrm{O}} \times C_{p, \mathrm{H}_{2} \mathrm{O}} \times T+\left(1-x_{\mathrm{H}_{2} \mathrm{O}}\right) \times C_{p, \text { feedstock }} \times T\right)\right] \times\left[1-R_{h}\right]}{\left[Y_{\text {oil }} \times(H H V) \times\left(1-x_{\mathrm{H}_{2} \mathrm{O}}\right) \times R_{c}\right]} \\
E C R_{\text {upgrading }}=\frac{\left.\left[x_{\mathrm{H}_{2} \mathrm{O}} \times C_{p, \mathrm{H}_{2} \mathrm{O}} \times 75+x_{\mathrm{H}_{2} \mathrm{O}} \times L_{\text {vap }}+\left(1-x_{\mathrm{H}_{2} \mathrm{O}}\right) \times C_{p, \text { feedstock }} \times T\right)\right] \times\left[1-R_{h}\right]}{\left[Y_{\text {oil }} \times(H H V) \times R_{c}\right]}
\end{gathered}
$$

where $x_{\mathrm{H}_{2} \mathrm{O}}$ is the moisture content of the initial feedstock slurry; $T$ is the temperature increase required to reach the conversion conditions (initial temperature assumed to be $25^{\circ} \mathrm{C}$ ); $C_{p}$, H2O is the specific heat of water $(4.18 \mathrm{~kJ} / \mathrm{kg} / \mathrm{K}) ; C_{p}$, feedstock is the average specific heats of the algae, pretreated bio-oil, and upgraded bio-oil for HTL, pretreatment, and upgrading $(1.25,2.43$, and $2.12 \mathrm{~kJ} / \mathrm{kg} / \mathrm{K})$, respectively; $R_{h}$ and $R_{c}$ are the efficiencies of heat recovery and combustion energy assumed to be 0.5 and 0.7 , respectively [28]; $Y$ is the resulting bio-oil yield; $H H V(\mathrm{~kJ} / \mathrm{kg})$ is the higher heating value of the resulting bio-oil; and $L_{v a p}$ is the latent heat of volatilization for water $(2260 \mathrm{~kJ} / \mathrm{kg})$. However, algae, pretreated bio-oil, and upgraded bio-oil do not have specific heat capacity data available in the literature. When no literature data were available, the estimation method in Perry's Chemical Engineer's Handbook [29] was used to calculate the heat capacity, which is an estimation method based on the contributions from different types of atoms. 
The $\mathrm{C}$ and $\mathrm{H}$ contents of the crude bio-oil were significantly higher than those of the microalgae, whereas the N, O, and S contents were reduced to different degrees. Therefore, the crude bio-oil had a considerably higher energy density than the microalgae, which increased from $26.6 \mathrm{MJ} / \mathrm{kg}$ in the microalgae to $38.4 \mathrm{MJ} / \mathrm{kg}$ in the crude bio-oil.

Compared to the crude bio-oil, the $\mathrm{C}$ and $\mathrm{H}$ contents in the pretreated bio-oil were further increased, whereas the $\mathrm{N}, \mathrm{O}$, and $\mathrm{S}$ contents were reduced. A large-scale decrease in the $\mathrm{O}$ and $\mathrm{S}$ contents was observed, suggesting that $\mathrm{N}$ is more difficult to remove than $\mathrm{O}$ and $\mathrm{S}$, which is consistent with previous studies $[11,12]$. These decreases in the $\mathrm{N}$ and $\mathrm{S}$ contents would decrease the possibility of catalyst poisoning [30], thus prolonging the lifetime of the catalyst. The viscosity of the pretreated bio-oil also decreased, which can improve the heat and mass transfer in the subsequent upgrading process, reducing the secondary polymerization or condensation of the upgraded bio-oil. Although the properties of the pretreated bio-oil improved, it still contained heteroatoms $(\mathrm{O}$ and $\mathrm{N})$ at higher levels than the ASTM requirement [31]; thus, further chemical or physical upgrading is needed if the material is to be used as a transportation fuel or feedstock for a petroleum refinery.

Table 3 shows that all of the zeolites presented activities towards the removal of $\mathrm{N}, \mathrm{O}$, and $\mathrm{S}$ to different degrees. The upgraded bio-oil produced with zeolites had higher $\mathrm{C}$ and $\mathrm{H}$ contents than the bio-oil produced without catalyst, suggesting that the zeolites promoted the hydrogenation reactions. Similar results were observed in a previous study on the upgrading of crude algal bio-oil with HZSM-5 [12]. Compared to the other zeolites, MCM-41 presented the highest hydrogenation activity because the upgraded bio-oil produced with MCM-41 contained a higher H content than the bio-oil produced with the other catalysts. Of the examined zeolites, HZSM-5 with a low Si/Al molar ratio, HY with a high proportion of $\mathrm{Na}_{2} \mathrm{O}$, and MCM-41 provided good performance for denitrogenation and desulfurization. The denitrogenation and desulfurization activity of HZSM-5 decreased with an increasing Si/Al molar ratio possibly because the total acidity (strong acid and weak acid, see Table 2) decreased with the increase in the Si/Al molar ratio [21,22], thus reducing 
its catalytic activity. Decreased denitrogenation and desulfurization activity were also observed for MCM-41 due to the decreased total acid sites from the increase in the Si fraction of MCM-41. For the HY series, the low $\mathrm{Na}_{2} \mathrm{O}$ content resulted in a high proportion of total acid sites, which was unfavorable for denitrogenation, indicating that species (e.g., $\mathrm{Na}_{2} \mathrm{O}$ ) other than acid sites also played a catalytic role in denitrogenation. $\mathrm{O}$ is more easily removed than $\mathrm{N}$ in the presence of zeolite. $\mathrm{HY}$ zeolite with a low $\mathrm{Na}_{2} \mathrm{O}$ content exhibited high performance in $\mathrm{O}$ removal. Essentially, lower total acidity of the zeolite resulted in a lower $\mathrm{O}$ content of the resulting upgraded bio-oil. Most zeolites have a high surface area; thus, the physical adsorption of N, O, and S cannot be ruled out. Compared to the uncatalyzed reaction, the upgraded bio-oil produced with zeolites had a higher H/C molar ratio. Therefore, the upgraded bio-oil produced with zeolite had a higher energy density than the bio-oil produced without zeolite, which is even larger than the heating value of petroleum $\operatorname{diesel}(44.8 \mathrm{MJ} / \mathrm{kg})[32]$.

Table 3 lists the S-ER and O-ER for the hydrothermal liquefaction, pretreatment, and upgrading processes. S-ER values of $0.58,0.83$, and $0.47-0.60$ were obtained for the hydrothermal liquefaction, pretreatment, and upgrading processes, respectively. Upgrading reactions were performed at severe temperatures $\left(400{ }^{\circ} \mathrm{C}\right)$, and more light-end fractions were formed, which are easily lost during the solvent process, thus decreasing the S-ER for the upgrading process. The O-ERs were also significantly lower than their corresponding S-ER due to the multiple sample transfers required to separate the product fractions and the use of evaporation to remove solvents from the samples. Therefore, a new recovery method for the upgraded bio-oil should be developed without solvent extraction to avoid the mass loss during the solvent evaporation.

The last column in Table 2 provides the ECR for the HTL, pretreatment, and upgrading processes. The ECR values for all of the three above processes are significantly less than unity, indicating a high positive energy balance. HTL resulted in an ECR of 0.187 , which is much smaller than the value (0.44-0.63) obtained by Vardon [25] for the HTL of other algal biomass species. Much lower ECRs were observed for the pretreatment and upgrading processes due to the smaller moisture 
content in these two reaction systems. Pretreatment is more favorable than upgrading due to the required water volatilization in the latter technique. The ECR, which varied from 0.041 to 0.52 , is independent of the type of zeolite catalyst.

\subsubsection{GC-MS analysis}

Gas chromatography-mass spectrometry (GC-MS) was applied to gain insight into the molecular compositions of the crude, pretreated, and upgraded bio-oils. Fig. S1 compares the total ion chromatograms (TICs) of the crude, pretreated, and upgraded bio-oils produced from the hydrothermal processing of the pretreated bio-oil with different zeolites. The intensity scale for the chromatograms differs for the different bio-oils. However, the peak area percentage of each individual compound is independent of the concentration of the samples because it is simply the ratio of each peak area to the total area of all of the detected compounds. Several peaks were identified in Fig. S1 using the National Institute of Standards and Technology (NIST) mass spectral database for GC-MS.

The compounds identified in the crude bio-oil primarily included amides (e.g., tetradecanamide, hexadecanamide, octadecanamide, 9-octadecenamide, and N-methyldodecanamide), acids (e.g., hexadecanoic acid, octadecanoic acid, and 13-octadecanoic acid), phytane, and phytene. Pretreating the crude bio-oil decreased the proportion of amides and acids, whereas their decarboxylation products (saturated hydrocarbons) increased. Table 4 provides detailed information regarding the peak area $\%$ of the major hydrocarbons in the crude, pretreated, and upgraded bio-oils. Clearly, the upgraded bio-oils produced with different zeolites mainly consisted of hydrocarbons, and the total hydrocarbon content depended on the type of zeolite. Of the tested zeolites, MCM-41 produced an upgraded bio-oil that contained up to $80 \%$ total hydrocarbons, whereas the upgraded bio-oil produced with SAPO-11 contained the lowest amount of total hydrocarbons. The hydrocarbons mainly consisted of straight-chain alkanes, which ranged from $\mathrm{C}_{8}-\mathrm{C}_{21}$, with pentadecane and heptadecane as the two most abundant compounds, dominating the chromatograms of all of the upgraded bio-oils. 


\subsection{3. $T G A$}

The distillation range is the main performance index of a liquid biofuel and is mainly used to determine the relative proportion of the light and heavy fractions in the bio-oil. TGA was used to estimate the boiling point range of each bio-oil. The bio-oils were heated from room temperature to $790{ }^{\circ} \mathrm{C}$ at a heating rate of $10{ }^{\circ} \mathrm{C} / \mathrm{min}$. At higher temperatures, the bio-oil sample may undergo some cracking $[14,15]$. Fig. 3 lists the boiling point distribution of the crude, pretreated, and upgraded bio-oils, as determined from the TGA data. As the temperature increased to $500{ }^{\circ} \mathrm{C}$, approximately 15.05 and 10.01 wt.\% solids remained in the crude and pretreated bio-oil, respectively, indicating that pretreatment decreased the distillation range of the crude bio-oil, which converted the high-boiling-point macromolecules to comparatively lower-molecular-weight compounds. The diesel range fraction in the pretreated bio-oil $(78.70 \%)$ was higher than that in the crude bio-oil $(69.78 \%)$. Catalytic upgrading further decreased the proportion of the high-boiling-point fraction in the bio-oil. For all of the zeolites except HZSM-5 $\left(\mathrm{SiO}_{2} / \mathrm{Al}_{2} \mathrm{O}_{3}=25: 1\right), \mathrm{MCM}-41(50 \% \mathrm{Si})$, and $\mathrm{HY}$ $\left(0.8 \% \mathrm{Na}_{2} \mathrm{O}\right)$, the $>500{ }^{\circ} \mathrm{C}$ fraction in the bio-oil was less than $5 \%$. For HZSM-5, the $>500{ }^{\circ} \mathrm{C}$ fraction in the bio-oil was always lower than the oil produced with the other zeolites because the $\mathrm{SiO}_{2} / \mathrm{Al}_{2} \mathrm{O}_{3}$ molar ratio was larger than $25: 1$, whereas the petroleum- and diesel-range fractions were always higher. These results indicate that the presence of HZSM-5 can effectively promote the cracking of macromolecules in the bio-oil and conversion to materials with low-boiling-point fractions. Of all of the tested zeolites, SAPO-11 had the lowest performance in the cracking reactions because the upgraded bio-oil produced with SAPO-11 contained the highest $>500{ }^{\circ} \mathrm{C}$ fraction (13.60\%) and the lowest petroleum- and diesel-range fractions (83.98\%).

\section{Conclusions}

Hydrogenation pretreatment can reduce the viscosity and heteroatom contents of crude bio-oil, thus decreasing the probability of catalyst poisoning and coke formation, as well as improving the mass and heat transfer during the subsequent upgrading process. The selected 9 zeolites can promote the removal of $\mathrm{N}, \mathrm{O}$, and $\mathrm{S}$ in the pretreated bio-oil to different degrees. The presence of 
zeolites can promote hydrogenation, thus increasing the $\mathrm{H} / \mathrm{C}$ molar ratio of the bio-oil. Zeolite can also accelerate the cracking reaction of the pretreated bio-oil and convert the macromolecules to lighter and smaller compounds, thus decreasing the distillation range and enhancing the atomization and combustion performance of the bio-oil. Given these encouraging results, zeolites are promising catalysts for improving the properties of crude bio-oil from the hydrothermal liquefaction of microalgae. Future work should focus on conducting experiments to probe the activity and structure of the catalysts after use under hydrothermal reaction conditions.

\section{Acknowledgments}

We gratefully acknowledge the financial support from the National Science Foundation of China (21106034) and from the Program for New Century Excellent Talents in University (NCET-13-775).

\section{References}

[1] X. Miao, Q. Wu, Biodiesel production from heterotrophic microalgal oil, Bioresour. Technol., 97 (2006) 841-846.

[2] E. Min, Financial crisis boosts the development of microalgal biodiesel, The 27th Chinese Chemical Society Congress, Xiamen, China, June 20-23, 2010.

[3] Y. Chisti, Biodiesel from microalgae, Biotechnol. Adv., 25 (2007) 294-306.

[4] N.H. Tran, J.R. Bartlett, G.S.K. Kannangara, A.S. Milev, H. Volk, M.A. Wilson, Catalytic upgrading of biorefinery oil from micro-algae, Fuel, 89 (2010) 265-274.

[5] P.E. Savage, Organic chemical reactions in supercritical water, Chem. Rev., 99 (1999) 603-622.

[6] P.Duan, P.E. Savage, Hydrothermal liquefaction of a microalgae with heterogeneous catalysts, Ind. Eng. Chem. Res., 50 (2010) 52-61.

[7] A.B. Ross, P. Biller, M.L. Kubacki, H. Li, A. Lea-Langton, J.M. Jones, Hydrothermal processing of microalgae using alkali and organic acids, Fuel, 89 (2010) 2234-2243.

[8] D. Zhou, L. Zhang, S. Zhang, H. Fu, J. Chen, Hydrothermal liquefaction of macroalgae Enteromorpha prolifera to bio-oil, Energy Fuels, 24 (2010) 4054-4061. 
[9] T. Brown, P. Duan, P.E. Savage, Hydrothermal liquefaction and gasification of Nannochloropsis sp, Energy Fuels, 24 (2010) 3639-3646.

[10] P. Duan, P.E. Savage, Upgrading of crude algal bio-oil in supercritical water, Bioresour. Technol., 102 (2011) 1899-1906.

[11] P. Duan, P.E. Savage, Catalytic treatment of crude algal bio-oil in supercritical water: optimization studies, Energy Environ. Sci., 4 (2011) 1447-1456.

[12] P. Duan, P.E. Savage, Catalytic hydrotreatment of crude algal bio-oil in supercritical water, Appl. Catal. B Environ., 104 (2011) 136-143.

[13] P. Duan, X. Bai, Y. Xu, A. Zhang, F. Wang, L. Zhang, J. Miao, Catalytic upgrading of crude algal oil using platinum/gamma alumina in supercritical water, Fuel, 109 (2013) 225-233.

[14] X. Bai, P. Duan, Y. Xu, A. Zhang, P.E. Savage, Hydrothermal catalytic processing of pretreated algal oil: a catalyst screening study, Fuel, 120 (2014) 141-149.

[15] Y. Xu, P. Duan, B. Wang, Catalytic upgrading of pretreated algal oil with a two-component catalyst mixture in supercritical water, Algal Research, 9 (2015) 186-193.

[16] H. Yin, X. Li, R. Zhang, Y. Fan, N. Yu, Y. Cai. Online catalytic cracking of bio-oil over HZSM-5 zeolite and analysis of catalyst deactivation. J. Fuel. Chem. Technol., 42 (2014) 1077-1086.

[17] L. Wang, J. Zhang, X. Yi, A. Zheng, F. Deng, C. Chen, Y. Ji, F. Liu, X. Meng, F. Xiao, Mesoporous ZSM-5 zeolite-supported $\mathrm{Ru}$ nanoparticles as highly efficient catalysts for upgrading phenolic biomolecules. ACS Catal., 5(2015) 2727-2734.

[18] P.A. Zapata, J. Faria, M.P. Ruiz, R.E. Jentoft, D.E. Resasco, Hydrophobic zeolites for biofuel upgrading reactions at the liquid-liquid interface in water/oil emulsions. J. Am. Chem. Soc., 134 (2012) 8570-8578.

[19] J.D. Adjaye, N.N. Bakhshi, Production of hydrocarbons by catalytic upgrading of a fast pyrolysis bio-oil. Part I: Conversion over various catalysts.Fuel Process. Technol.45 (1995)161-183. 
[20] W.B Widayatno, G.Guan, J. Rizkiana, X. Du, X. Hao, Z. Zhang, A. Abudula, Selective catalytic conversion of bio-oil over high-silica zeolites. Bioresour. Technol., 179 (2015) 518-523.

[21] L. Shirazi, E. Jamshidi1, M. R. Ghasemi, The effect of Si/Al ratio of ZSM-5 zeolite on its morphology, acidity and crystal size. Cryst. Res. Technol. 43(2008) 1300-1306.

[22] F. Pan, X. Lu, Q. Zhu, Z. Zhang, Y. Yan, T. Wang, S. Chen, Direct synthesis of HZSM-5 from natural clay. J. Mater. Chem. A, 3(2015)4058-4066.

[23] P. Namkhang , P. Kongkachuichay, Synthesis of copper-based nanostructured catalysts on $\mathrm{SiO}_{2}-\mathrm{Al}_{2} \mathrm{O}_{3}, \mathrm{SiO}_{2}-\mathrm{TiO}_{2}$, and $\mathrm{SiO}_{2}-\mathrm{ZrO}_{2}$ supports for $\mathrm{NO}$ reduction. J. Nanosci. Nanotechnol. $7(2015) 5410-5417$.

[24] I. Matejovic, Determination of carbon, hydrogen, and nitrogen in soils by automated elemental analysis (dry combustion method). Comm. Soil Sci. Plant Anal., 24 (1993), 2213-2222.

[25] American Society for Testing and Materials, ASTM International Designation: standard test method for sulfur in petroleum gas by oxidative microcoulometry, ASTM Int. ASTM D3246 (2015) 1-8.

[26] T. Minowa, T. Kondo, S.T. Sudirjo, Thermochemical liquefaction of Indonesian biomass residues. Biomass Bioenergy, 14 (1998) 517-524.

[27] P. Biller, A.B. Ross, Potential yields and properties of oil from the hydrothermal liquefaction of microalgae with different biochemical content. Bioresour. Technol., 102 (2011) 215-225.

[28] D. Vardon, Hydrothermal liquefaction for energy recovery from high-moisture waste biomass; University of Illinois at Urbana-Champaign: Urbana, IL, 2012.

[29] R.H. Perry, D.W. Green, J.O. Maloney (Eds.), Perry’s Chemical Engineer's Handbook, 7th Edition, in: Section 2, Physical and Chemical Data, The McGraw-Hill Companies, Inc., New York, 1999, pp. 2-347-2-348.

[30] D.C. Elliott, Catalytic hydrothermal gasification of biomass, Biofuels Bioprod. Bior., 2 (2008) 254-265. 
[31] American Society for Testing and Materials, ASTM International Designation: standard specification for biodiesel fuel blend stock (B100) for middle distillate fuels, ASTM Int. D6751-07a (2007) 1-8.

[32] A. Demirbas, Importance of biodiesel as transportation fuel, Energ. Policy, 35 (2007) $4661-467$. 


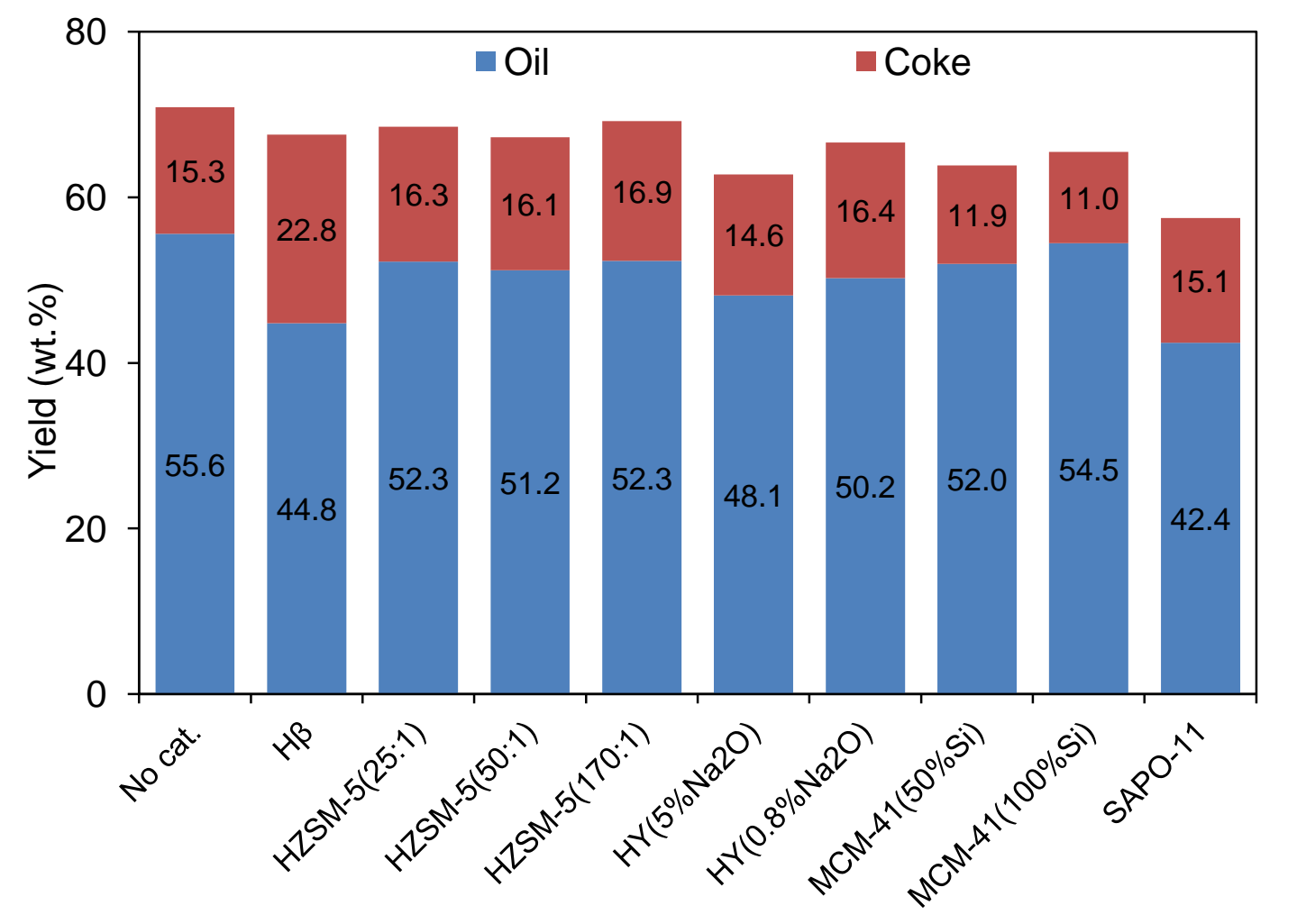

Fig. 1. Effect of catalyst on the yields of upgraded bio-oil and coke. 


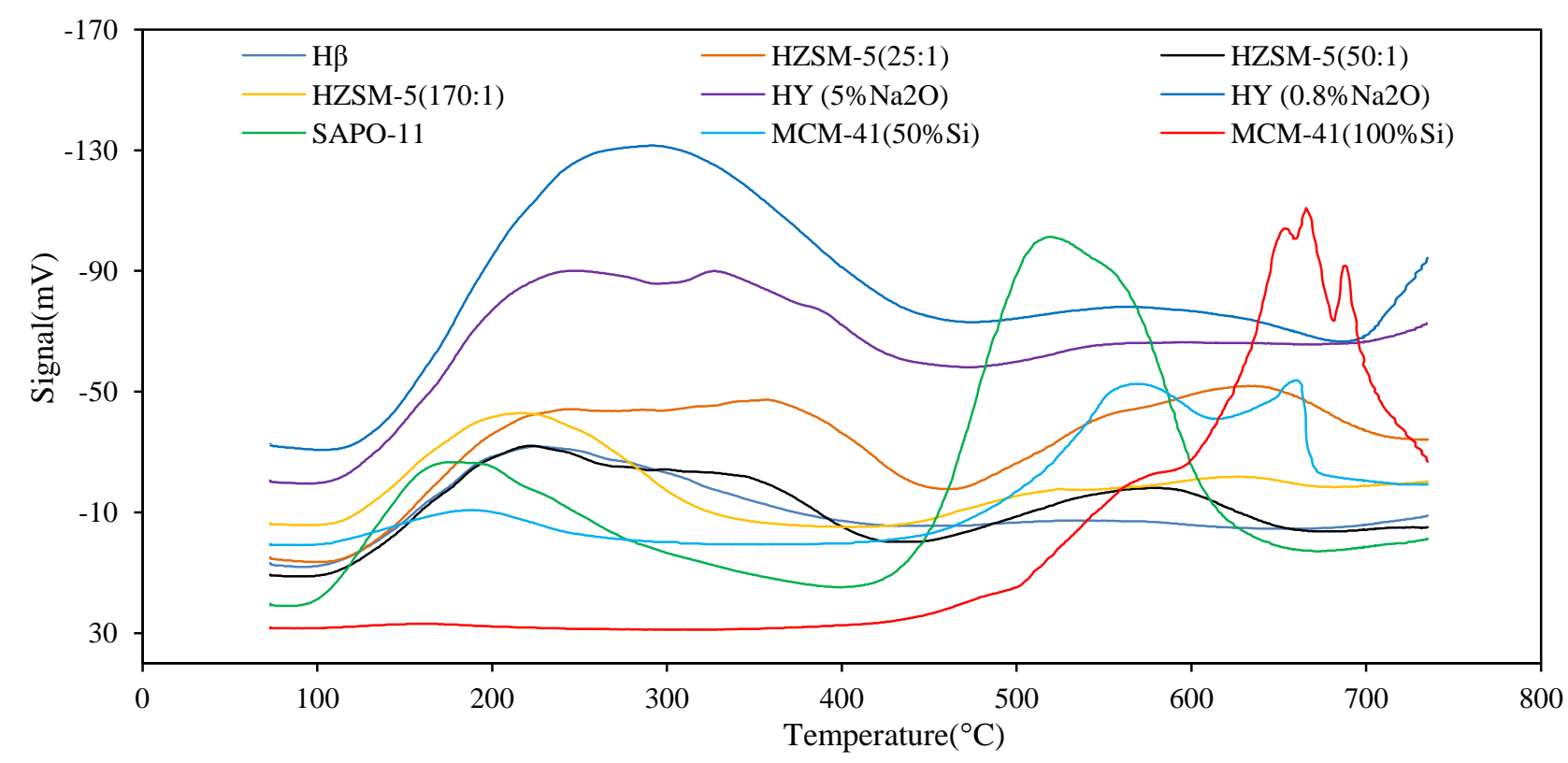

Fig. 2. $\mathrm{NH}_{3}$-TPD profiles of different zeolite samples 


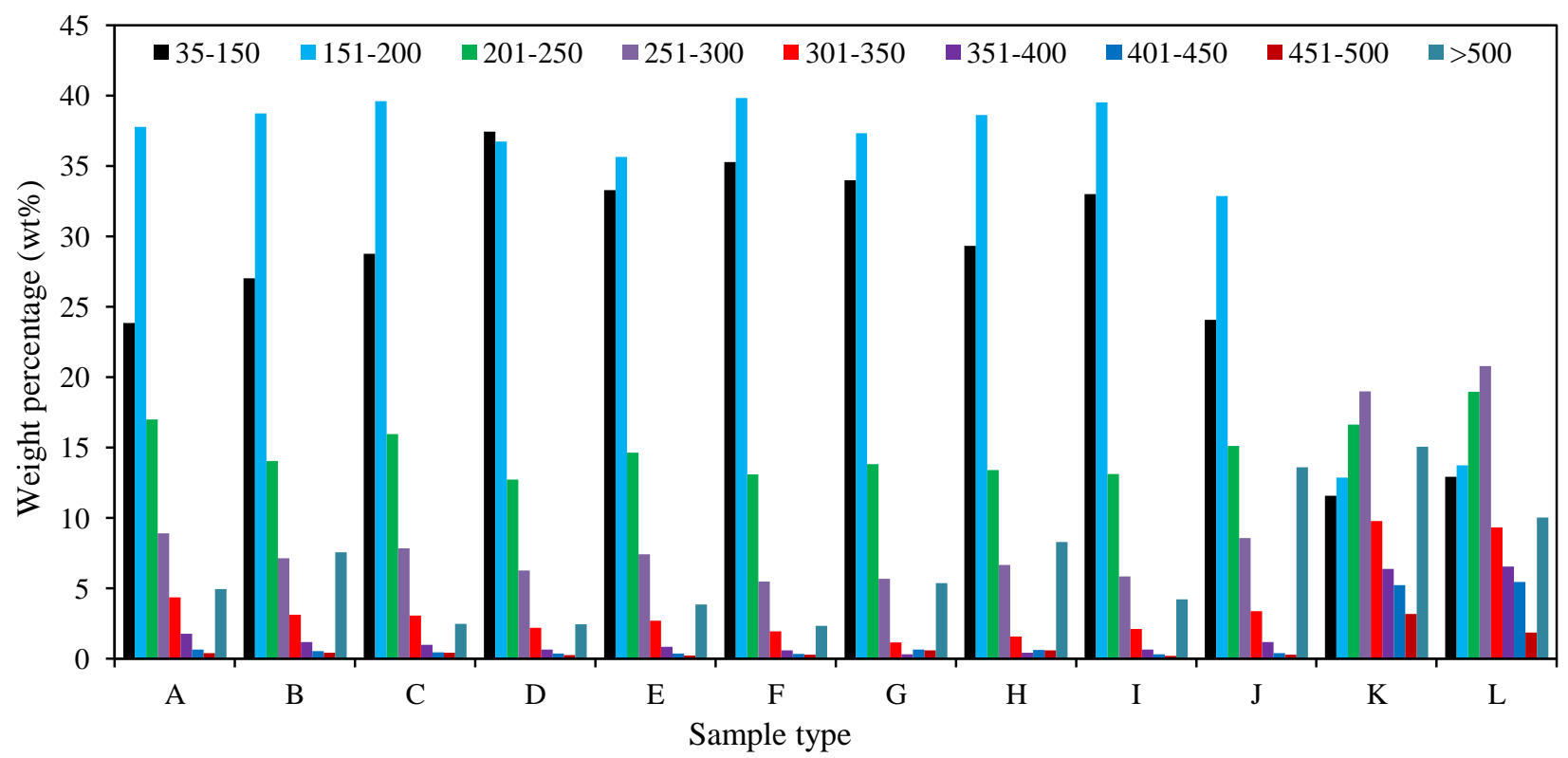

Fig. 3. Boiling point distribution of crude, pretreated, and upgraded bio-oils (UO) produced with different zeolites (A. H $\beta$; B. UO-HZSM-5 ( $\left.\mathrm{SiO}_{2} / \mathrm{Al}_{2} \mathrm{O}_{3}=25: 1\right)$; C. UO-HZSM-5 $\left(\mathrm{SiO}_{2} / \mathrm{Al}_{2} \mathrm{O}_{3}=50: 1\right)$; D. UO-HZSM-5 $\left(\mathrm{SiO}_{2} / \mathrm{Al}_{2} \mathrm{O}_{3}=80: 1\right)$; E. UO-HZSM-5 $\left(\mathrm{SiO}_{2} / \mathrm{Al}_{2} \mathrm{O}_{3}=170: 1\right)$; F. UO-HY $\left(5 \% \mathrm{Na}_{2} \mathrm{O}\right)$; G.UO-HY $\left(0.8 \% \mathrm{Na}_{2} \mathrm{O}\right)$; H. UO-MCM-41(50\%Si); I. UO-MCM-41(100\% Si); J. UO-SAPO-11; K. Pretreated oil; L. Crude oil) 


\section{Table 1}

Catalyst characterization.

\begin{tabular}{|c|c|c|c|c|c|}
\hline \multirow[b]{2}{*}{ Catalyst type } & \multirow[b]{2}{*}{$\begin{array}{l}\text { Surface area } \\
\qquad / \mathrm{m}^{2} \mathrm{~g}^{-1}\end{array}$} & \multirow{2}{*}{$\begin{array}{c}\text { Micropore } \\
\text { volume } \\
/ \mathrm{cm}^{3} \mathrm{~g}^{-1}\end{array}$} & \multicolumn{3}{|c|}{ Pore size distribution (\%) } \\
\hline & & & $<2 \mathrm{~nm}$ & $\begin{array}{r}2-50 \\
\mathrm{~nm}\end{array}$ & $>50 \mathrm{~nm}$ \\
\hline $\mathrm{H} \beta$ & 436 & 0.183 & 51.78 & 39.10 & 9.12 \\
\hline HZSM-5 $\left(\mathrm{SiO}_{2} / \mathrm{Al}_{2} \mathrm{O}_{3}=25: 1\right)$ & 238 & 0.100 & 60.95 & 34.89 & 4.16 \\
\hline HZSM-5 $\left(\mathrm{SiO}_{2} / \mathrm{Al}_{2} \mathrm{O}_{3}=50: 1\right)$ & 279 & 0.117 & 66.68 & 30.44 & 2.88 \\
\hline HZSM-5 $\left(\mathrm{SiO}_{2} / \mathrm{Al}_{2} \mathrm{O}_{3}=170: 1\right)$ & 343 & 0.145 & 68.55 & 28.65 & 2.80 \\
\hline $\mathrm{HY}\left(5 \% \mathrm{Na}_{2} \mathrm{O}\right)$ & 505 & 0.216 & 71.00 & 27.21 & 1.79 \\
\hline $\mathrm{HY}\left(0.8 \% \mathrm{Na}_{2} \mathrm{O}\right)$ & 504 & 0.216 & 77.72 & 20.51 & 1.77 \\
\hline SAPO-11 & 9 & 0.002 & 4.72 & 79.99 & 15.29 \\
\hline MCM-41(50\%Si) & 38 & 0.012 & 12.96 & 76.19 & 10.85 \\
\hline MCM-41(100\%Si) & 50 & 0.017 & 14.45 & 77.63 & 7.92 \\
\hline
\end{tabular}


Table 2

TPD-NH $\mathrm{N}_{3}$ adsorption for different zeolites

\begin{tabular}{lccc}
\hline Sample & Weak acid sites & Strong acid sites & Total \\
\hline $\mathrm{H} \beta$ & 0.09 & 0.03 & 0.13 \\
$\mathrm{HZSM}-5\left(\mathrm{SiO}_{2} / \mathrm{Al}_{2} \mathrm{O}_{3}=25: 1\right)$ & 0.17 & 0.18 & 0.35 \\
$\mathrm{HZSM}-5\left(\mathrm{SiO}_{2} / \mathrm{Al}_{2} \mathrm{O}_{3}=50: 1\right)$ & 0.12 & 0.12 & 0.24 \\
$\mathrm{HZSM}-5\left(\mathrm{SiO}_{2} / \mathrm{Al}_{2} \mathrm{O}_{3}=170: 1\right)$ & 0.09 & 0.09 & 0.18 \\
$\mathrm{HY}\left(5 \% \mathrm{Na}_{2} \mathrm{O}\right)$ & 0.37 & 0.25 & 0.62 \\
$\mathrm{HY}\left(0.8 \% \mathrm{Na}_{2} \mathrm{O}\right)$ & 0.47 & 0.28 & 0.75 \\
$\mathrm{SAPO}-11$ & 0.06 & 0.18 & 0.24 \\
MCM-41 $(50 \% \mathrm{Si})$ & 0.08 & 0.29 & 0.37 \\
MCM-41 $(100 \% \mathrm{Si})$ & 0.01 & 0.21 & 0.22 \\
\hline
\end{tabular}




\section{Table 3}

Elemental composition (wt\%, daf) and other properties of crude bio-oil, pretreated oil, and upgraded oils (UO) produced with different zeolites.

\begin{tabular}{|c|c|c|c|c|c|c|c|c|c|c|c|}
\hline & $\mathrm{N}$ & $\mathrm{C}$ & $\mathrm{H}$ & $\mathrm{O}$ & $\mathrm{S}$ & $\mathrm{H} / \mathrm{C}$ & $\mathrm{O} / \mathrm{C} \mathrm{N} / \mathrm{C}$ & $\mathrm{HHV}(\mathrm{kJ} / \mathrm{g})$ & S-ER & O-ER & ECR \\
\hline Algae & 9.80 & 59.30 & 7.40 & 22.70 & 0.80 & 1.50 & 0.2870 .142 & 26.56 & & & \\
\hline Crude bio-oil & 5.95 & 75.40 & 9.96 & 7.37 & 0.65 & 1.59 & 0.0730 .068 & 38.40 & 0.58 & 0.58 & 0.187 \\
\hline Pretreated bio-oil & 4.58 & 79.20 & 10.22 & 5.04 & 0.20 & 1.55 & 0.0480 .050 & 40.49 & 0.83 & 0.48 & 0.034 \\
\hline No cat. & 3.45 & 82.40 & 10.66 & 4.32 & 0.17 & 1.55 & 0.0390 .036 & 42.32 & 0.58 & 0.28 & 0.042 \\
\hline $\mathrm{UO}-\mathrm{H} \beta$ & 2.10 & 84.15 & 11.36 & 2.29 & 0.11 & 1.62 & 0.0200 .021 & 44.26 & 0.49 & 0.24 & 0.050 \\
\hline UO-HZSM-5 $\left(\mathrm{SiO}_{2} / \mathrm{Al}_{2} \mathrm{O}_{3}=25: 1\right)$ & 1.76 & 84.32 & 11.48 & 2.03 & 0.08 & 1.63 & 0.0180 .018 & 44.54 & 0.58 & 0.28 & 0.043 \\
\hline UO-HZSM-5 $\left(\mathrm{SiO}_{2} / \mathrm{Al}_{2} \mathrm{O}_{3}=50: 1\right)$ & 1.77 & 84.20 & 11.58 & 1.91 & 0.09 & 1.65 & 0.0170 .018 & 44.67 & 0.57 & 0.27 & 0.043 \\
\hline UO-HZSM- $5\left(\mathrm{SiO}_{2} / \mathrm{Al}_{2} \mathrm{O}_{3}=170: 1\right)$ & 2.15 & 84.69 & 11.64 & 1.50 & 0.11 & 1.65 & 0.0130 .022 & 44.98 & 0.58 & 0.28 & 0.042 \\
\hline $\mathrm{UO}-\mathrm{HY}\left(5 \% \mathrm{Na}_{2} \mathrm{O}\right)$ & 1.67 & 84.36 & 11.72 & 1.94 & 0.12 & 1.67 & 0.0170 .017 & 44.92 & 0.53 & 0.26 & 0.046 \\
\hline $\mathrm{UO}-\mathrm{HY}\left(0.8 \% \mathrm{Na}_{2} \mathrm{O}\right)$ & 2.02 & 84.57 & 11.70 & 1.27 & 0.11 & 1.66 & 0.0110 .020 & 45.07 & 0.56 & 0.27 & 0.044 \\
\hline UO-SAPO-11 & 2.21 & 84.49 & 11.59 & 1.51 & 0.14 & 1.65 & 0.0130 .022 & 44.85 & 0.47 & 0.23 & 0.052 \\
\hline UO-MCM-41(50\%Si) & 1.77 & 84.22 & 11.84 & 2.53 & 0.09 & 1.69 & 0.0230 .018 & 44.92 & 0.60 & 0.29 & 0.041 \\
\hline UO-MCM-41(100\%Si) & 1.87 & 83.60 & 12.09 & 1.73 & 0.12 & 1.74 & 0.0160 .019 & 45.23 & 0.58 & 0.28 & 0.042 \\
\hline
\end{tabular}


Table 4

Hydrocarbons contents of upgraded bio-oils(UO) produced with different zeolites

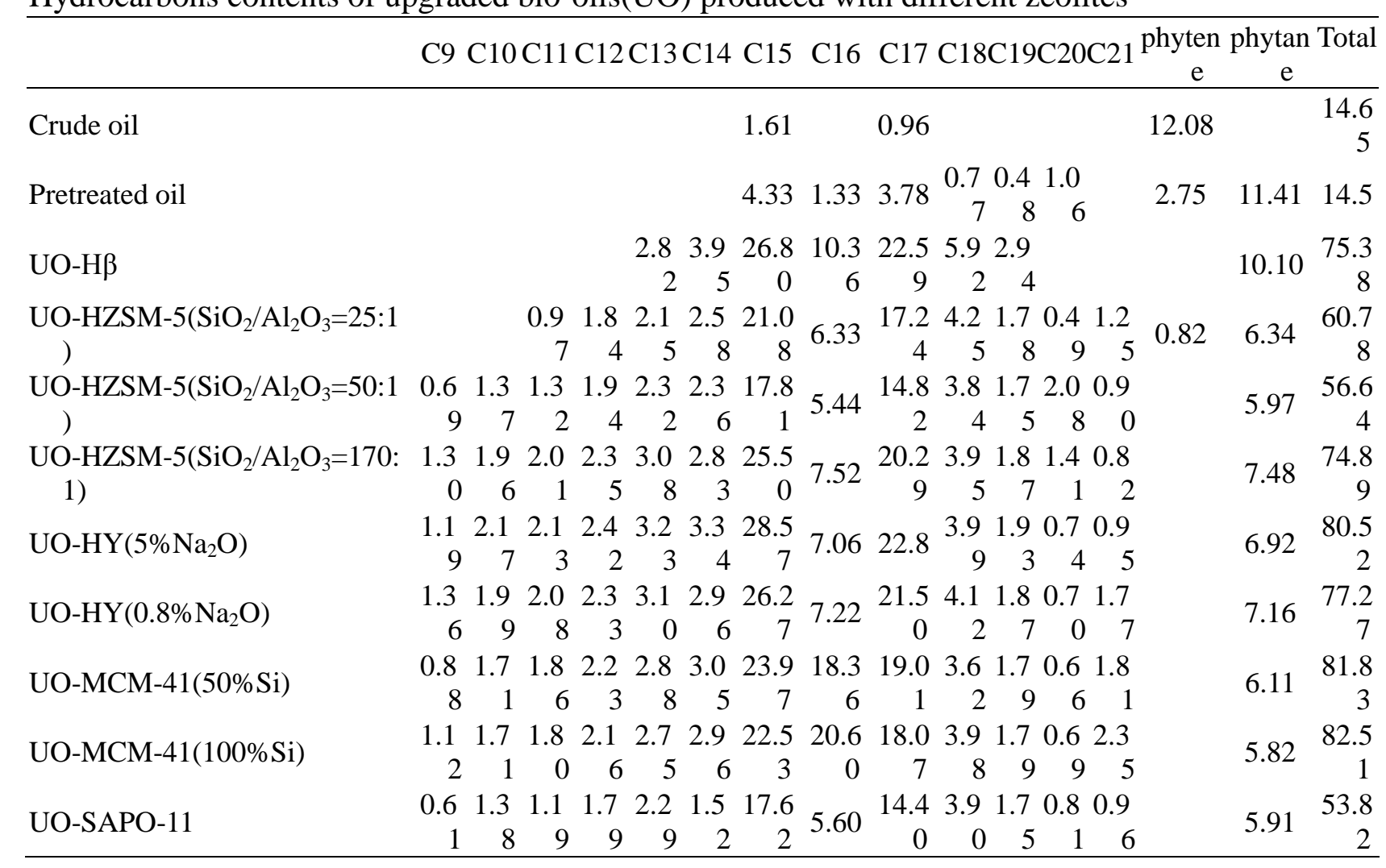




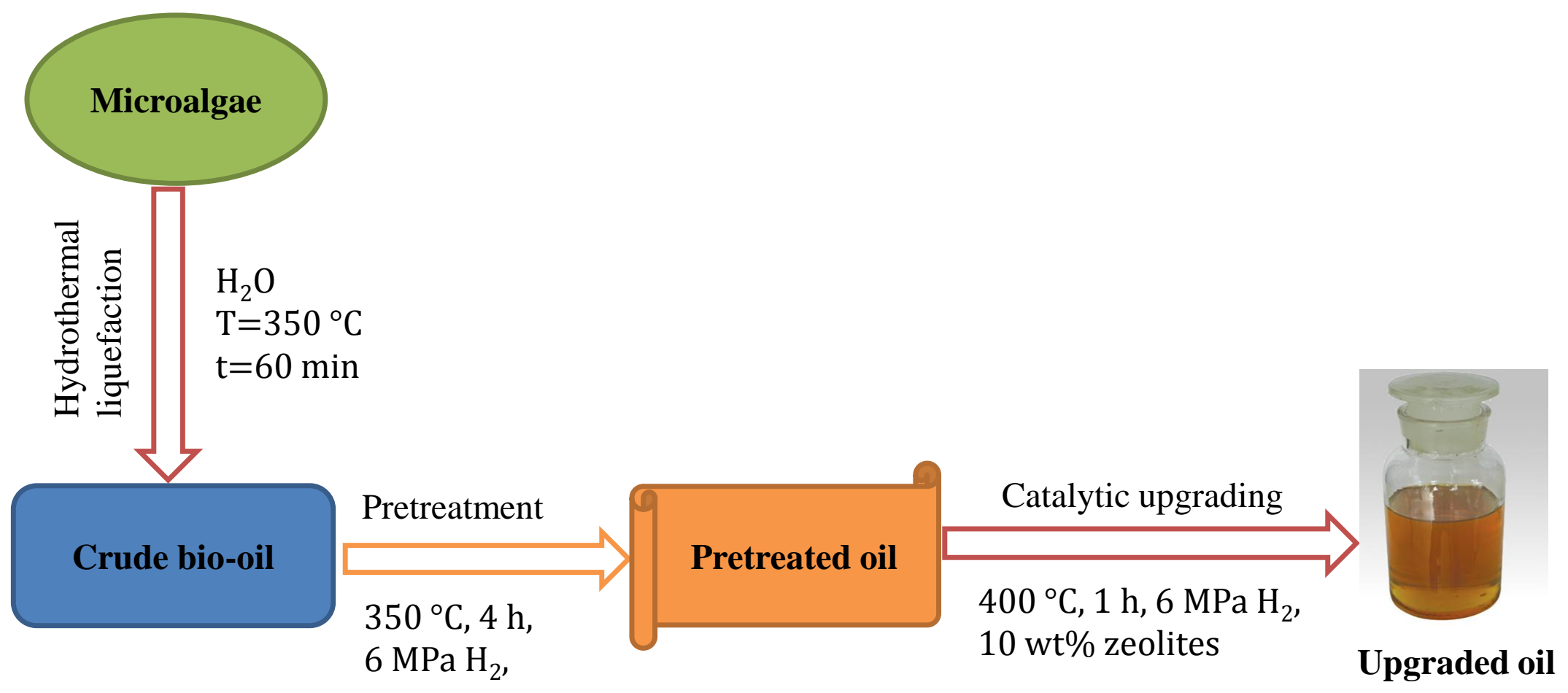

